\title{
A long journey to be anatomic
}

\author{
Freddie H. Fu $\cdot$ Jon Karlsson
}

Published online: 29 July 2010

(c) Springer-Verlag 2010

In 1836, Weber and Weber from Göttingen, Germany performed dissection studies and described the anterior cruciate ligament (ACL) as two separate bundles that tension at different knee flexion angles [21, 33]. Many years later in 1912, the first ACL reconstruction was performed by Giertz, the mentor of Palmer, using a single-bundle of tensor fascia lata [5]. In 1917, Hey-Groves used an open ACL reconstruction technique that was "quite" anatomic [9]. He used tunnels to locate the graft, drilling the femoral tunnel inside-out, aiming to place the tunnel aperture on the outer aspect of the notch to produce an oblique graft. In 1938, Palmer proposed the idea of double-bundle reconstruction in his thesis on the ACL [20], though the concept received little attention at the time and his work was not appropriately accredited until many years later.

The first arthroscopically assisted ACL reconstruction was performed in 1980 by Dandy [4]. However, arthroscopic surgery was far more challenging than open reconstruction. Arthroscopic anatomic reconstruction of the ACL has a learning curve, as Snow et al. demonstrate in their paper [26]. Surgeons and industry started focusing on developing standardized techniques to facilitate easier and more efficient graft placement, employing techniques such as the o'clock reference, notchplasty, isometry and drill guides. Some of these terms like the o'clock reference and

F. H. Fu

Department of Orthopaedic Surgery, University of Pittsburgh

Medical Center, Kaufman Building Suite 1011,

3471 Fifth Avenue, Pittsburgh, PA 15213, USA

J. Karlsson $(\bowtie)$

Department of Orthopaedics, Sahlgrenska University Hospital,

43180 Mölndal, Sweden

e-mail: jon.kssta@gmail.com isometry turned into almost mandatory but often misleading technical descriptions. The resulting surgical techniques were indeed fast and efficient, but as Behrend et al. [2] show in their study on the over-the-top guide, unable to place the tunnels in the ACL insertion site. It was such techniques that lead the field away from the teachings of Weber, Palmer and their colleagues. Anatomic tunnel placement was not a priority, and the two-bundle anatomy of the ACL was never considered.

This had surgeons asking: "Does anatomy matter?" since the general consensus was that these arthroscopic techniques were effective for restoring knee function. However, as longer-term follow-up data and better kinematic analysis techniques emerged, it has become clear that conventional non-anatomic ACL reconstruction techniques do not prevent the development of early osteoarthritis after ACL injury $[6,14,16]$ nor do they restore normal dynamic knee function [27]. These results indicate that our reconstruction techniques need to be improved and restoring anatomy may be the key to success. Therefore, efforts to make reconstruction techniques more anatomic as well as critically evaluate them, such as by Silva et al. [24, 25] and Serrano-Fernandez et al. [23], should be applauded.

"Anatomic" ACL reconstruction can be defined as the functional restoration of the ACL to its native dimensions, collagen orientation and insertion sites (Fig. 1) [29]. It is a detailed and meticulous procedure that involves visualization of the native ACL insertion site, measuring ACL and knee dimensions, appropriate graft tensioning and evaluation of graft and tunnel position using MRI and 3D CT scan. It encompasses single- and double-bundle reconstruction and can be applied to primary, revision and augmentation surgery. The development of the anatomic technique has made us take a closer look at the ACL anatomy. Just a few years ago, you would not have seen 


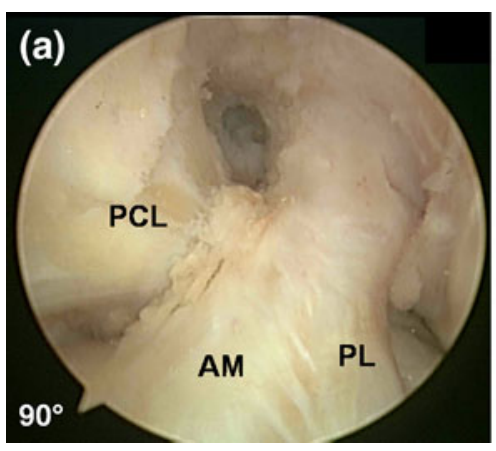

Fig. 1 a Arthroscopic view of the native ACL of a left knee through the anteromedial portal (knee in $90^{\circ}$ of flexion). The two bundle anatomy of the ACL is clearly visible. b Arthroscopic anteromedial portal view of the ACL of a left knee after anatomic double-bundle

papers such as by Iriuchishima et al., studying the anatomy of the ACL insertion site in such a detailed fashion [10] and Kasten et al. who evaluated the location of the tibial ACL insertion site using intra-operative fluoroscopy [12].

Anatomic ACL reconstruction also needs to consider concomitant injuries, bony morphology, neuromuscular control and homeostasis of the knee. Bony landmarks include the lateral intercondylar ridge and lateral bifurcate ridge, indicating the superior border of the femoral ACL insertion site and the border between the AM and PL bundle, respectively. These two structures are still visible in chronic ACL injuries, when the remnants of the ACL may be gone, according to a study by Van Eck et al. [32]. In ACL reconstruction, other ligamentous structures of the knee should also be evaluated for injury in case of ACL rupture. As demonstrated by Lertwanich et al. [15] in addition to the posterior cruciate ligament (PCL), the meniscofemoral ligament (MFL) also plays an important role in maintaining posterior stability of the knee. Not only the anatomy of the ACL is important but also that of surrounding structures, like the femoral intercondylar notch. The two papers by Van Eck et al. evaluate different measurement modalities of the notch, such as notch width index (NWI), volume and shape, and how these can aid us in the treatment of ACL injuries [30, 31]. Kendoff et al. [13] showed in their study that even changes in alignment can have an effect on the ACL, with valgisation affecting the length and strain of the PL bundle.

To evaluate our progress, reliable and accurate outcome measures are needed. The appropriate use of these outcomes measures is equally important. If we as surgeons want the best care for our patients, we have to be critical of our own performance. Systematic reviews and meta-analysis comparing different ACL reconstruction techniques all show no difference in outcome $[7,8,17,22]$. Does this mean that there is no difference, or do we need to

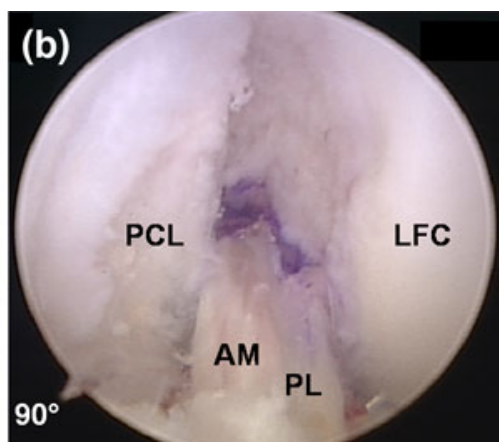

reconstruction (knee in $90^{\circ}$ of flexion). When compared to Fig. 1a, the native ACL anatomy is closely replicated. $A M$ anteromedial bundle, $P L$ posterolateral bundle, $L F C$ lateral femoral condyle, $P C L$ posterior cruciate ligament

reevaluate the ability of our outcome measures to detect subtle differences in kinematics of the knee, that in the long term may be associated with the development or prevention of post-traumatic osteoarthritis? The IKDC Knee Ligament Guidelines suggest that joint laxity, such as for the pivot shift, Lachman and KT-1000 arthrometer tests be reported as normal, nearly normal, abnormal or severely abnormal in comparison with the contra-lateral normal knee. However, when results are reported in the literature, normal and nearly normal outcomes are often combined into a single group, implying that "nearly normal is good enough" [11, 17]. But is "nearly normal" good enough? To answer this question, we may need more precise instruments, such as optical coherence tomography [3] and T2 and T1rho MRI mapping [1] to detect early cartilage changes and dynamic stereo radiographs to precisely quantify in vivo knee kinematics [28]. Our clinical examination can vary largely by observer [19] and as Musahl et al. showed in this issue, it is also significantly influenced by bony morphologic variations [18]. High-quality studies making use of precise outcome measures are needed to make valid conclusions regarding the benefits of anatomic ACL reconstruction. For example, to know if double-bundle reconstruction is superior to single-bundle reconstruction, prospective randomized trials are needed to compare anatomic singlebundle reconstruction with anatomic double-bundle reconstruction. To avoid bias in assessing outcome, these studies need to be double-blind, implying that both the patient and the individual measuring the outcomes is not aware if single- or double-bundle surgery was performed. Most importantly, we need to continue to modify our technique as more information about structure and function of the ACL becomes available. It is important to learn from the past and not let history repeat itself. It is a long and continuing journey to be anatomic. We have lost sight of the anatomy once; let us not repeat this mistake! 


\section{References}

1. Bear DM, Williams A, Chu CT, Coyle CH, Chu CR (2010) Optical coherence tomography grading correlates with MRI T2 mapping and extracellular matrix content. J Orthop Res 28(4):546-552

2. Behrendt S, Richter J (2010) Anterior cruciate ligament reconstruction: drilling a femoral posterolateral tunnel cannot be accomplished using an over-the-top step-off drill guide. Knee Surg Sports Traumatol Arthrosc. doi:10.1007/s00167-010-1112-6

3. Chu CR, Izzo NJ, Irrgang JJ, Ferretti M, Studer RK (2007) Clinical diagnosis of potentially treatable early articular cartilage degeneration using optical coherence tomography. J Biomed Opt 12:051703

4. Dandy DJ (1996) Basic technique: the standard approach. In: McGinty JB (ed) Operative arthroscopy. Lippincott-Raven, Philadelphia, pp 252-253

5. Giertz K (1913) Über freie Transplantation der fascia lata als fór Sehnen und B $\delta$ nder. Dtsch Z Chir 125:480-495

6. Gillquist J, Messner K (1999) Anterior cruciate ligament reconstruction and the long-term incidence of gonarthrosis. Sports Med 27:143-156

7. Goldblatt JP, Fitzsimmons SE, Balk E, Richmond JC (2005) Reconstruction of the anterior cruciate ligament: meta-analysis of patellar tendon versus hamstring tendon autograft. Arthroscopy 21:791-803

8. Harner CD, Olson E, Irrgang JJ, Silverstein S, Fu FH, Silbey M (1996) Allograft versus autograft anterior cruciate ligament reconstruction: 3-5-year outcome. Clin Orthop Relat Res (324):134-144

9. Hey-Groves EW (1917) Operation for the repair of crucial ligaments. Lancet 2:674-675

10. Iriuchishima T, Ingham SJM, Tajima G, Horaguchi T, Saito A, Tokuhashi Y, Van Houten AH, Aerts MM, Fu FH (2010) Evaluation of the tunnel placement in the anatomical double-bundle ACL reconstruction: a cadaver study. Knee Surg Sports Traumatol Arthrosc. doi:10.1007/s00167-010-1128-y

11. Irrgang JJ, Bost JE, Fu FH (2009) Re: Outcome of single-bundle versus double-bundle reconstruction of the anterior cruciate ligament: a meta-analysis. Am J Sports Med 37:421-422 (author reply 422)

12. Kasten P, Szczodry M, Irrgang J, Kropf E, Costello J, Fu FH (2010) What is the role of intra-operative fluoroscopic measurements to determine tibial tunnel placement in anatomical anterior cruciate ligament reconstruction? Knee Surg Sports Traumatol Arthrosc. doi:10.1007/s00167-010-1082-8

13. Kendoff D, Koulalis D, Citak M, Voos J, Pearle AD (2010) Open wedge valgus tibial osteotomies: affecting the distinct ACL bundles. Knee Surg Sports Traumatol Arthrosc. doi:10.1007/ s00167-010-1073-9

14. Lebel B, Hulet C, Galaud B, Burdin G, Locker B, Vielpeau C (2008) Arthroscopic reconstruction of the anterior cruciate ligament using bone-patellar tendon-bone autograft: a minimum 10year follow-up. Am J Sports Med 36:1275-1282

15. Lertwanich P, Martins CAQ, Kato Y, Ingham SJM, Kramer S, Linde-Rosen M, Smolinski P, Fu FH (2010) Contribution of the meniscofemoral ligament as a restraint to the posterior tibial translation in a porcine. knee Knee Surg Sports Traumatol Arthrosc. doi:10.1007/s00167-010-1134-0

16. Liden M, Sernert N, Rostgard-Christensen L, Kartus C, Ejerhed L (2008) Osteoarthritic changes after anterior cruciate ligament reconstruction using bone-patellar tendon-bone or hamstring tendon autografts: a retrospective, 7-year radiographic and clinical follow-up study. Arthroscopy 24:899-908

17. Meredick RB, Vance KJ, Appleby D, Lubowitz JH (2008) Outcome of single-bundle versus double-bundle reconstruction of the anterior cruciate ligament: a meta-analysis. Am J Sports Med 36:1414-1421

18. Musahl V, Ayeni OR, Citak M, Irrgang JJ, Pearle AD, Wickiewicz TL (2010) The influence of bony morphology on the magnitude of the pivot shift. Knee Surg Sports Traumatol Arthrosc. doi:10.1007/s00167-010-1129-x

19. Noyes FR, Grood ES, Cummings JF, Wroble RR (1991) An analysis of the pivot shift phenomenon. The knee motions and subluxations induced by different examiners. Am J Sports Med 19:148-155

20. Palmer I (1938) On the injuries on the ligaments to the knee joint. A clinical study. Acta Chir Scand 81:282

21. Passler HH (1993) The history of the cruciate ligaments: some forgotten (or unknown) facts from Europe. Knee Surg Sports Traumatol Arthrosc 1:13-16

22. Samuelsson K, Andersson D, Karlsson J (2009) Treatment of anterior cruciate ligament injuries with special reference to graft type and surgical technique: an assessment of randomized controlled trials. Arthroscopy 25:1139-1174

23. Serrano-Fernandez JM, Espejo-Baena A, Martin-Castilla B, De La Torre-Solis F, Mariscal-Lara J, Merino-Ruiz ML (2010) Augmentation technique for partial ACL ruptures using semitendinosus tendon in the over-the-top position. Knee Surg Sports Traumatol Arthrosc. doi:10.1007/s00167-010-1068-6

24. Silva A, Sampaio R, Pinto E (2010) Femoral tunnel enlargement after anatomic ACL reconstruction: a biological problem? Knee Surg Sports Traumatol Arthrosc. doi:10.1007/s00167-010-1046-Z

25. Silva A, Sampaio R, Pinto E (2010) Placement of femoral tunnel between the AM and PL bundles using a transtibial technique in single-bundle ACL reconstruction. Knee Surg Sports Traumatol Arthrosc. doi:10.1007/s00167-010-1132-2

26. Snow M, Stanish WD (2010) Double-bundle ACL reconstruction: how big is the learning curve? Knee Surg Sports Traumatol Arthrosc. doi:10.1007/s00167-010-1062-z

27. Tashman S, Collon D, Anderson K, Kolowich P, Anderst W (2004) Abnormal rotational knee motion during running after anterior cruciate ligament reconstruction. Am J Sports Med 32:975-983

28. Tashman S, Kolowich P, Collon D, Anderson K, Anderst W (2007) Dynamic function of the ACL-reconstructed knee during running. Clin Orthop Relat Res 454:66-73

29. van Eck CF, Lesniak BP, Schreiber VM, Fu FH (2010) Anatomic single- and double-bundle anterior cruciate ligament reconstruction flowchart. Arthroscopy 26:258-268

30. van Eck CF, Martins CAQ, Lorenz SGF, Fu FH, Smolinski P (2010) Assessment of correlation between knee notch width index and the three-dimensional notch volume. Knee Surg Sports Traumatol Arthrosc. doi:10.1007/s00167-010-1131-3

31. van Eck CF, Martins CAQ, Vyas SM, Celentano U, van Dijk CN, Fu FH (2010) Femoral intercondylar notch shape and dimensions in ACL-injured patients. Knee Surg Sports Traumatol Arthrosc. doi:10.1007/s00167-010-1135-z

32. van Eck CF, Morse KR, Lesniak BP, Kropf EJ, Tranovich MJ, van Dijk CN, Fu FH (2010) Does the lateral intercondylar ridge disappear in ACL deficient patients? Knee Surg Sports Traumatol Arthrosc. doi:10.1007/s00167-009-1038-z

33. Weber W, Weber E (1836) Mechanik der menschlichen Gehwerkzeuge, Goettingen 